\title{
Loss of expression and nuclear/cytoplasmic localization of the FOXP1 forkhead transcription factor are common events in early endometrial cancer: relationship with estrogen receptors and HIF-1 $\alpha$ expression
}

\author{
Alexandra Giatromanolaki ${ }^{1}$, Michael I Koukourakis ${ }^{2}$, Efthimios Sivridis ${ }^{1}$, Kevin C Gatter ${ }^{3}$, \\ Adrian L Harris ${ }^{4}$ and Alison $\mathrm{H}_{\text {Banham }}^{3}$ \\ ${ }^{1}$ Department of Pathology, Democritus University of Thrace, Alexandroupolis, Greece; ${ }^{2}$ Department of \\ Radiotherapy/Oncology, Democritus University of Thrace, Alexandroupolis, Greece; ${ }^{3}$ Nuffield Department \\ of Clinical Laboratory Sciences, John Radcliffe Hospital, Oxford, UK and ${ }^{4}$ Cancer Research UK, Molecular \\ Oncology Laboratories, Institute of Molecular Medicine, John Radcliffe Hospital, Oxford, UK
}

\begin{abstract}
The FOXP1 gene has been identified as a new member of the winged helix family of transcription factors that have important roles in cellular transformation, differentiation and proliferation. In this study, we examined the expression of FOXP1 in the normal and malignant endometrium (stage I endometrioid adenocarcinoma cases), showing a frequent deregulation of its expression in cancer. Proliferative endometrium showed predominantly nuclear localization of FOXP1, while exclusively weak cytoplasmic staining was present in the secretory phase. Loss of nuclear expression was the most striking event in endometrial adenocarcinoma. Nuclear expression ranged from 0 to $20 \%$ (median $0 \%$ ). Cytoplasmic expression was noted more frequently, ranging from 0 to $90 \%$ of cancer cells (median $30 \%$ ). Overall, $24 / 82$ cases $(29.3 \%)$ were observed to lack both nuclear and cytoplasmic FOXP1 expression. Tumors with exclusively cytoplasmic expression of FOXP1 were linked with deep myometrial invasion and hypoxia-inducible factors $1 \alpha$ (HIF-1 $\alpha$ ) expression. On the other hand, the presence of nuclear FOXP1 expression was significantly linked with ER- $\alpha$ reactivity. Survival analysis did not reveal significant differences among patients grouped by FOXP1 expression, presumably due to the high curability of stage I disease. This study provides evidence on pathways to be investigated to elucidate the interplay between FOXP1, ER- $\alpha$ and HIF-1 $\alpha$ in hormone dependent cancers.
\end{abstract}

Modern Pathology (2006) 19, 9-16. doi:10.1038/modpathol.3800494; published online 23 September 2005

Keywords: FOXP1; HIF-1 $\alpha$; ER- $\alpha$; endometrial carcinoma

Allelic deletions or imbalance are frequent in endometrial cancer, the $3 p$ chromosome arm being involved most commonly. ${ }^{1}$ In a study by Arlt et al, ${ }^{2}$ loss of heterozygosity $(\mathrm{LOH})$ at one or more loci on chromosome $3 p$ was evident in $17 \%$ of endometrial carcinomas. Jones et $a l^{3}$ using CA-repeat polymorphisms, identified a common region of deletion at chromosome 3p12-21.1 in endometrial cancer.

Recently, the FOXP1 gene on chromosome $3 \mathrm{p} 14.1,{ }^{4}$ has been identified as a new member of

Correspondence: Dr A Giatromanolaki, MD, Department of Pathology, Democritus University of Thrace, PO Box 12, Alexandroupolis 68100, Greece.

E-mail: targ@her.forthnet.gr

Received 5 July 2005; accepted 1 August 2005; published online 23 September 2005 the winged helix family of transcription factors that have important roles in cellular transformation, differentiation and proliferation (reviewed in Carlson and Mahlapuu ${ }^{5}$ ). The FOXP1 protein is widely expressed in normal tissues, exhibiting a predominantly nuclear localization, while loss of expression or cytoplasmic mislocalization commonly characterizes malignant tissues. ${ }^{4}$ Although the role of this protein in human cancer development and progression remains obscure, recent clinicopathological studies reported an important role in B-cell lymphomas. ${ }^{6-8}$ A role for FOXP1 as a tumor suppressor gene in the development of breast cancer has been also suggested. ${ }^{9}$ Studies of FOXP1 knockout mice have recently demonstrated that this molecule plays an essential role in development and that its deletion results in an embryonic lethal phenotype ${ }^{10}$ 
Interestingly, a loss of FOXP1 expression in cardiac myocytes results in their increased proliferation while loss of FOXP1 in cushion mesenchyme of heart outflow tracts was associated with decreased apoptosis, both observations are consistent with a role for FOXP1 as a tumor suppressor gene where loss of expression could potentially increase proliferation and reduce programmed cell death. ${ }^{11}$

In this study, we examined the expression of FOXP1 in the normal and malignant endometrium, showing a frequent deregulation of its expression in cancer. Association of FOXP1 expression patterns with histopathological and other tumor-related features, including the presence of hormone receptors and the expression of endogenous markers of hypoxia and angiogenesis, were also examined.

\section{Materials and methods}

Formalin-fixed, paraffin-embedded tissues from 25 normal endometria at various phases of the menstrual cycle and 82 endometrial adenocarcinomas of the endometrioid cell type, stage I, were retrieved from the files of the Department of Pathology, Democritus University of Thrace, Alexandroupolis, Greece.

The histologically normal endometria were obtained from premenopausal women, age 34-40 years, who had undergone hysterectomy for nonendometrial disease. None of the patients had received hormone therapy. The normal endometria had been 'dated' on hematoxylin- and eosin-stained sections by using the histological criteria of Noyes et al. ${ }^{12}$

All cancer patients had been treated surgically with total abdominal hysterectomy and bilateral salpingo-oophorectomy. No lymph node sampling of the iliac nodes was performed. Histologic typing and grading of the endometrial tumors (grade 1 vs grade 2 and 3 ) and the depth of myometrial invasion were assessed on hematoxylin-eosin sections, using standard criteria. ${ }^{13,14}$ The follow-up of patients alive ranged from 22 to 182 months with a median of 70 months. At the time of analysis ten patients (12.2\%) were dead with disease.

\section{Immunohistochemistry for FOXP1}

The FOXP1 protein was detected using the mouse JC12 monoclonal antibody (MoAb) (IgG2a MoAb; dilution 1:40). ${ }^{4}$ Sections were deparaffinized and peroxidase was quenched with methanol and 3\% $\mathrm{H}_{2} \mathrm{O}_{2}$ for $15 \mathrm{~min}$. Microwaving for antigen retrieval was used $(3 \times 5 \mathrm{~min})$. The primary antibodies were applied overnight. Following washing with TBS, sections were incubated with a secondary rabbit antimouse antibody (Kwik Biotinylated Secondary, 0.69A Shandon-Upshaw) for $15 \mathrm{~min}$ and washed in TBS. Kwik Streptavidin peroxidase reagent (039A Shandon-Upshaw) was applied for $15 \mathrm{~min}$ and sections were again washed in TBS. The color was developed by 15 min incubation with $\mathrm{DAB}$ solution and sections were weakly counterstained with hematoxylin.

Normal breast tissue sections with strong nuclear FOXP1 expression were used as positive controls. ${ }^{9}$ Normal mouse immunoglobulin-G was substituted for primary antibody at the same concentration as a negative control.

FOXP1 expression was both cytoplasmic and nuclear in normal tissues. The extent and pattern of staining also varied among tumors. The percentage of cancer cells with FOXP1 nuclear reactivity was recorded in all optical fields and the mean value was used to form a final score. Similarly, the percentage of cancer cells with strong cytoplasmic staining was recorded in all optical fields and the mean value was used to characterize the case as for the cytoplasmic reactivity.

\section{Immunohistochemistry for Other Antigens}

Sections were cut at $3 \mu \mathrm{m}$ and stained immunohistochemically with the following techniques: (a) a standard streptavidin-biotin method for the detection of estrogen receptor alpha (ER- $\alpha$ ), progesterone receptor (PgR), hypoxia-inducible factors $1 \alpha(\mathrm{HIF}-1 \alpha)$ and $2 \alpha(\mathrm{HIF}-2 \alpha)$ and (b) the alkaline phosphatase/antialkaline phosphatase (APAAP) method for vessel staining (anti-CD31 MoAb) and the detection of the vascular endothelial growth factor (VEGF) ${ }^{15-18}$ Details of the primary antibodies, the working dilutions and the antigen retrieval methods used are given in Table 1.

Table 1 Details of the antibodies, dilutions, and antigen retrieval methods used in this study

\begin{tabular}{|c|c|c|c|c|}
\hline Primary antibody & Dilution/incubation time & Antigen retrieval & Specificity & References \\
\hline ESEE 122 & 1:20 (90 min $\left.{ }^{\mathrm{a}}\right)$ & MW & HIF- $1 \alpha$ & Oxford University $^{12}$ \\
\hline EP 190b & Neat $\left(90 \min ^{\mathrm{a}}\right)$ & MW & $\mathrm{HIF}-2 \alpha$ & Oxford University ${ }^{12}$ \\
\hline JC70 & $1: 50\left(30 \min ^{\mathrm{a}}\right)$ & Protease XXIV & Endothelium & Dako, Denmark $^{13}$ \\
\hline VG1 & 1:4 $\left(90 \min ^{\mathrm{a}}\right)$ & MW & VEGF & Oxford University ${ }^{14}$ \\
\hline 1D5 & $1: 20\left(75 \min ^{\mathrm{a}}\right)$ & MW & ER- $\alpha$ & Dako, Denmark ${ }^{15}$ \\
\hline $1 \mathrm{~A} 6$ & $1: 20\left(75 \min ^{\mathrm{a}}\right)$ & MW & PgR & Dako, Denmark $^{15}$ \\
\hline
\end{tabular}

${ }^{\mathrm{a}}$ At room temperature.

$\mathrm{MW}=$ microwave heating. 
Known positive controls were included in each staining run. Omission of the primary antibody and substitution by nonspecific immunoglobulin at the same concentration were used as negative controls.

\section{Staining Patterns and Evaluation of Other Proteins}

HIF- $1 \alpha$ and HIF- $2 \alpha$ are endogenous markers of hypoxia, exhibiting expression with a mixed nuclear and cytoplasmic pattern. Although nuclear presence of HIF is in accordance with the HIF activity in the nucleus, HIF protein is synthesized and degraded in the cytoplasm. Cytoplasmic expression, just like nuclear, is a tumor-specific feature and either expression pattern definitely indicate a selective HIF up-regulation. Redistribution of HIF subcellular localization during tissue collection is extremely difficult to control, and omission of the cytoplasmic pattern results in erroneous grouping of cases. Analysis based on purely nuclear expression showed an absence of, or a very marginal, statistical association with other molecular factors or prognosis in several previous studies, indicating that it is the tumor-specific finding of strong cytoplasmic HIF expression that should also be recorded to analyze upregulation of the HIF pathway in paraffinembedded material. The importance of assessing both cytoplasmic and nuclear staining for the expression of HIFs has been raised in earlier studies. ${ }^{19,20}$ A grading system reported in Table 2, that groups cases using both expression patterns, has been proposed and applied in a series of previous studies by our group. ${ }^{15,21-23}$

The percentage of tumor cells expressing the various antigens under investigation was assessed semiquantitatively at $\times 200$ magnification. The counts were performed on the entire tumor area in all available fields of view. The mean value was used as a cut-off point to define cases of high and low tumor reactivity for VEGF cytoplasmic reactivity. For ER- $\alpha$ and PgR nuclear reactivity a cut-off point of $10 \%$ was used to define groups of high vs groups of low receptor expression.

Table 2 A grading system based on the intensity and extent of cytoplasmic and nuclear immunostaining of proteins exhibiting mixed subcellular localization (ie FOXP1 and HIF)

\begin{tabular}{ll}
\hline Grading & Score \\
\hline $\begin{array}{l}\text { Complete absence of reactivity } \\
\text { Weak cytoplasmic reactivity (regardless of } \\
\text { extent) }\end{array}$ & $\begin{array}{l}\text { Negative (low) } \\
\text { Low }\end{array}$ \\
$\begin{array}{l}\text { Strong cytoplasmic reactivity in less than } \\
50 \% \text { of tumor cells }\end{array}$ & Low \\
$\begin{array}{l}\text { Nuclear expression in sporadic tumor cells } \\
\begin{array}{l}<10 \% \text { of cells) } \\
\text { Strong cytoplasmic expression in more than }\end{array}\end{array}$ & Low \\
$\begin{array}{l}50 \% \text { of tumor cells } \\
\text { Nuclear expression in more than } 10 \% \text { of } \\
\text { tumor cells }\end{array}$ & High \\
\hline
\end{tabular}

Tumor angiogenesis was assessed by microvessel counting. Three areas of high vascular density (hot spots) were selected at the invading tumor front; the final microvessel score was the mean of the vessel counts obtained from these fields. Only blood vessels with a clearly defined lumen or a linear vessel shape, but not single endothelial cells, were taken into account.

In all cases, the assessment of vascular density was performed independently by two pathologists (AG, ES), having no access to the patient data. Discrepancies were resolved over the conference microscope.

\section{Statistical Analysis}

Statistical analysis and graphs were performed using the Instat 3.1 Package. and GraphPad Prism 2.01 package (GraphPad Software Inc., USA). A Fisher's exact test or Yate's continuity-corrected $t$-test was used for testing relationships between noncontinuous categorical (contingency tables). Linear regression analysis was used to assess correlation between continuous variables. Survival curves were plotted using the method of Kaplan and Meier, and the log-rank test was used to determine statistical differences between life tables. A $P$-value $<0.05$ was considered significant.

\section{Results}

\section{Expression Patterns of FOXP1 in Normal Endometrium}

Proliferative endometrium showed predominantly nuclear localization of FOXP1, while exclusively weak cytoplasmic staining was present in the secretory phase (Figure 1a, b). Stroma cells were negative. Expression of ER- $\alpha$ showed similar patterns of staining with nuclear localization during the proliferative phase and loss of nuclear expression during the secretory phase.

\section{Expression Patterns of FOXP1 in Malignant Endometrium}

The expression patterns of FOXP1 in cancer cells, when present, ranged from exclusively cytoplasmic to mixed nuclear/cytoplasmic, while solely nuclear staining was not noted. Loss of nuclear expression was the most striking event. Nuclear expression ranged from 0 to $20 \%$ (median $0 \%$ ). Cytoplasmic expression was noted more frequently, ranging from 0 to $90 \%$ of cancer cells (median 30\%). Overall, 24/ 82 cases $(29.3 \%)$ were observed to lack both nuclear and cytoplasmic FOXP1 expression. Table 3 shows the distribution of cases according to the subcellular pattern of FOXP1 expression. Figure 1 shows the patterns of FOXP1 expression in malignant endometrium. 

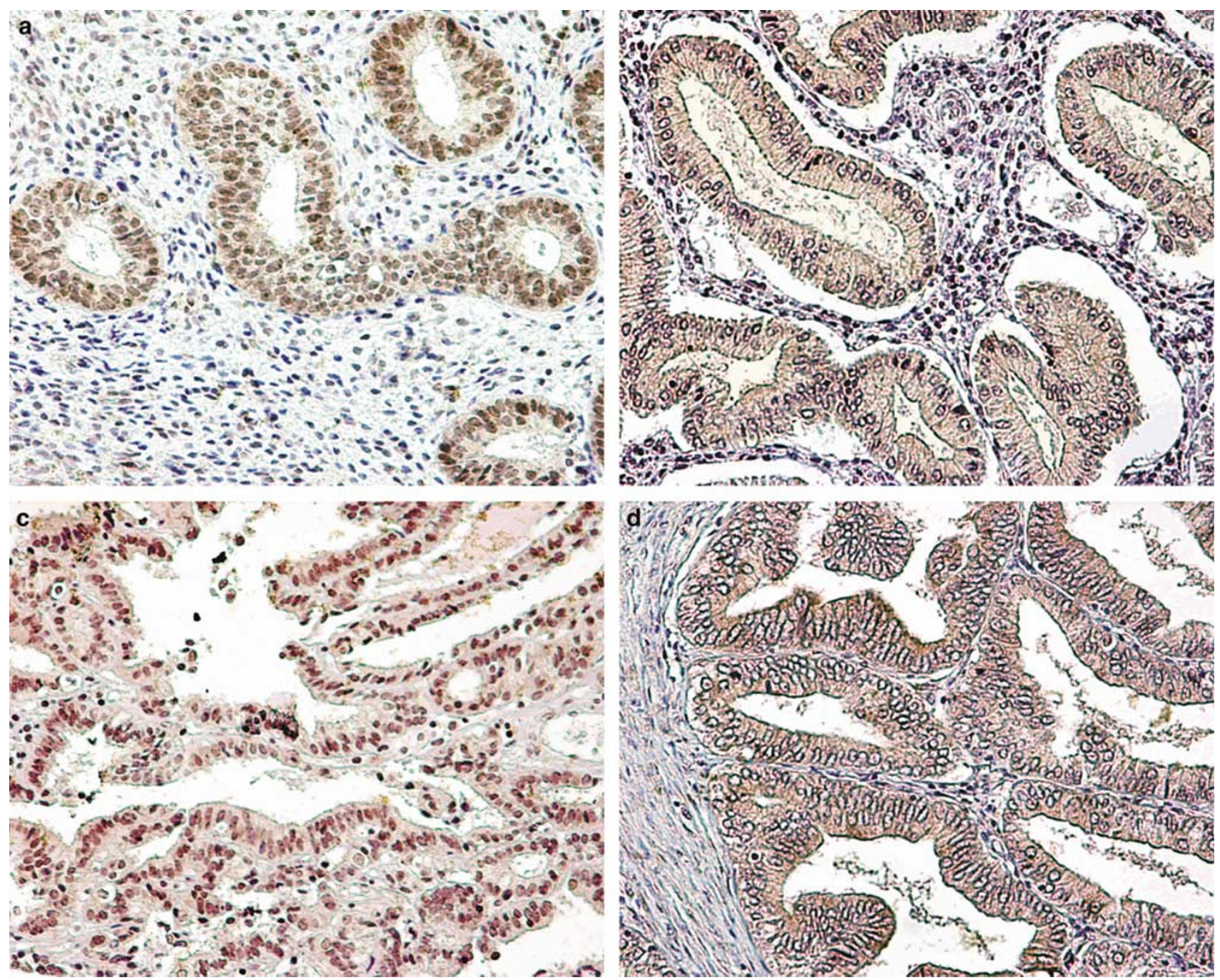

Figure 1 Immunohistochemical images of FOXP1 reactivity: (a) proliferative endometrium (mixed nuclear and cytoplasmic staining), (b) secretory endometrium (exclusively cytoplasmic staining), (c) endometrial adenocarcinoma with mixed nuclear/cytoplasmic FOXP1 staining and (d) endometrial adenocarcinoma with mixed cytoplasmic FOXP1 staining.

Table 3 Expression patterns of FOXP1 in endometrial stage I carcinoma and scoring

\begin{tabular}{lcllrr}
\hline Nuclear (\% of pos. cells) & No cases (\%) & Reactivity score & Cytoplasmic (\% of pos. cells) & No cases & Reactivity score \\
\hline Negative $(0 \%)$ & $58(70.8)$ & Negative & Negative & $24(29.3)$ & Negative \\
Focal $(1-9 \%)$ & $12(14.6)$ & Low & Weak (10-90\%) & $9(10.9)$ & Low \\
Positive $(10-20 \%)$ & $12(14.6)$ & High & Limited Strong (10-50\%) & $22(26.9)$ & Low \\
& & & Extensive Strong (60-90\%) & $27(32.9)$ & High \\
\hline
\end{tabular}

Stromal fibroblasts and reactive lymphocytes were not stained with FOXP1. Occasional intratumoral vessels showed FOXP1 positivity, independently of the expression of FOXP1 in cancer cells.

\section{Correlation with Histological and Molecular Variables}

Table 4 shows the association of FOXP1 expression patterns with histological and molecular variables. High FOXP1 nuclear expression was significantly linked with ER- $\alpha$ positivity $(P=0.002)$ and marginally with $\operatorname{PgR}(P=0.08)$. Cytoplasmic expression was significantly linked with HIF- $1 \alpha$ overexpression $(P=0.01)$, with deep myometrial invasion $(P=0.02)$ and marginally with poor differentiation $(P=0.06)$ and HIF- $2 \alpha$ reactivity $(P=0.09)$. Linear regression analysis of nuclear FOXP1 and ER- $\alpha$ expression showed a significant association $(P=0.003$; $r=0.35$ ). Analysis of cytoplasmic FOXP1 expression and HIF- $1 \alpha$ reactivity showed a significant association $(P=0.007, r=0.30)$. 
Table 4 Correlation of FOXP1 immunostaining patterns with histopathological and molecular variables

\begin{tabular}{|c|c|c|c|c|c|c|c|c|}
\hline \multirow[t]{2}{*}{ Parameter } & \multicolumn{4}{|c|}{ Nuclear FOXP1 } & \multicolumn{4}{|c|}{ Cytoplasmic FOXP1 } \\
\hline & $\mathrm{Neg}$ & Low & High & $\mathrm{P}$-value & $\mathrm{Neg}$ & Low & High & P-valu \\
\hline \multicolumn{9}{|c|}{ Myoinvasion } \\
\hline$<1 / 2$ & 34 & 3 & 6 & 0.10 & 17 & 17 & 9 & 0.02 \\
\hline$>1 / 2$ & 24 & 9 & 6 & & 7 & 14 & 18 & \\
\hline \multicolumn{9}{|l|}{ Grade } \\
\hline 1 & 48 & 8 & 10 & 0.42 & 18 & 29 & 19 & 0.06 \\
\hline $2-3$ & 10 & 4 & 2 & & 6 & 2 & 8 & \\
\hline \multicolumn{9}{|l|}{$E R-\alpha$} \\
\hline Neg & 49 & 11 & 5 & 0.002 & 20 & 27 & 18 & 0.13 \\
\hline Pos & 9 & 1 & 7 & & 4 & 4 & 9 & \\
\hline \multicolumn{9}{|l|}{$P g R$} \\
\hline Neg & 48 & 11 & 7 & 0.08 & 19 & 27 & 20 & 0.45 \\
\hline Pos & 10 & 1 & 5 & & 5 & 4 & 7 & \\
\hline \multicolumn{9}{|l|}{$H I F-1 \alpha$} \\
\hline Low & 30 & 7 & 5 & 0.70 & 18 & 15 & 9 & 0.01 \\
\hline High & 28 & 5 & 7 & & 6 & 16 & 18 & \\
\hline \multicolumn{9}{|l|}{$H I F-2 \alpha$} \\
\hline Low & 51 & 9 & 8 & 0.14 & 22 & 27 & 19 & 0.09 \\
\hline High & 7 & 3 & 4 & & 2 & 4 & 8 & \\
\hline \multicolumn{9}{|l|}{$V E G F$} \\
\hline Low & 31 & 9 & 8 & 0.31 & 15 & 16 & 16 & 0.69 \\
\hline High & 27 & 3 & 4 & & 9 & 15 & 11 & \\
\hline \multicolumn{9}{|l|}{$V D$} \\
\hline Low & 30 & 4 & 7 & 0.41 & 14 & 11 & 16 & 0.12 \\
\hline High & 28 & 8 & 5 & & 10 & 20 & 11 & \\
\hline
\end{tabular}

Bold figures show statistically significant values.

The above findings strongly suggest that the nuclear vs cytoplasmic distribution of FOXP1 fluctuates during the menstrual cycle and that its subcellular localization may also play a distinct role in the pathology of endometrial cancer. As nuclear expression is the feature characterizing normal proliferative endometrium, an exclusively cytoplasmic localization may be important in cancer cell biology. For this reason we further analyzed cases to dissect three groups of carcinomas on the basis of FOXP1 expression patterns: (i) tumors that maintained nuclear FOXP1 localization in more than $10 \%$ of cancer cells; (ii) tumors that lost nuclear expression but maintained FOXP1 extensive cytoplasmic reactivity in $>50 \%$ of cancer cells; and (iii) tumors with absence or low FOXP1 reactivity (in the nuclei of less than $10 \%$ of cancer cells or the cytoplasm of less than $50 \%$ of cancer cells). The association of this grouping of cases with histological and molecular variables is shown in Table 5 . This analysis clearly shows that tumors with exclusively cytoplasmic expression of FOXP1 were linked with deep myometrial invasion and HIF-1 $\alpha$ expression. On the other hand, the presence of nuclear FOXP1 expression was significantly linked
Table 5 Association of combined cytoplasmic/nuclear FOXP1 patterns of expression with hisopathological and molecular variables in endometrial cancer

\begin{tabular}{|c|c|c|c|c|c|}
\hline \multirow[t]{2}{*}{ Parameter } & \multicolumn{3}{|c|}{$F O X P 1$} & \multirow[t]{2}{*}{ P-value } & \\
\hline & $L_{o w}^{\mathrm{a}}$ & $C y t^{\mathrm{b}}$ & $N u c / C y t^{c}$ & & \\
\hline \multicolumn{6}{|c|}{ Myoinvasion } \\
\hline$<1 / 2$ & 32 & 5 & 6 & a vs b; & 0.02 \\
\hline$>1 / 2$ & 20 & 13 & 6 & $\begin{array}{l}\text { a } v S \mathrm{c} ; \\
\text { b VS } \mathrm{C} ;\end{array}$ & $\begin{array}{l}0.68 \\
0.39\end{array}$ \\
\hline \multicolumn{6}{|l|}{ Grade } \\
\hline 1 & 44 & 12 & 10 & a $v s \mathrm{~b}$ & 0.19 \\
\hline $2-3$ & 8 & 6 & 2 & $\begin{array}{l}\text { a vs } \mathrm{C} \\
\text { b vs C; }\end{array}$ & $\begin{array}{l}0.74 \\
0.55\end{array}$ \\
\hline \multicolumn{6}{|l|}{$E R-\alpha$} \\
\hline Neg & 45 & 15 & 5 & a $v s$ b; & 0.95 \\
\hline Pos & 7 & 3 & 7 & $\begin{array}{l}\text { a } v s \mathrm{c} \\
\text { b } v s \quad\end{array}$ & $\begin{array}{l}\mathbf{0 . 0 0 2} \\
0.04\end{array}$ \\
\hline \multicolumn{6}{|l|}{$P g R$} \\
\hline Neg & 44 & 15 & 7 & a vs b; & 0.80 \\
\hline Pos & 8 & 3 & 5 & $\begin{array}{l}\text { a vs } \mathrm{c} ; \\
\text { b vs } \mathrm{C} ;\end{array}$ & $\begin{array}{l}0.10 \\
0.67\end{array}$ \\
\hline \multicolumn{6}{|l|}{$H I F-1 \alpha$} \\
\hline Low & 32 & 5 & 5 & a vs b; & 0.02 \\
\hline High & 20 & 13 & 7 & $\begin{array}{l}\text { a } v s \mathrm{C} ; \\
\text { b } v S \mathrm{C}\end{array}$ & $\begin{array}{l}0.68 \\
0.39\end{array}$ \\
\hline \multicolumn{6}{|l|}{$H I F-2 \alpha$} \\
\hline Low & 46 & 14 & 8 & a $v s \mathrm{~b}$ & 0.46 \\
\hline High & 6 & 4 & 4 & $\begin{array}{l}\text { a } v S \mathrm{C} \\
\text { b vS C; }\end{array}$ & $\begin{array}{l}0.14 \\
0.80\end{array}$ \\
\hline \multicolumn{6}{|l|}{$V E G F$} \\
\hline Low & 29 & 11 & 5 & a vs b; & 0.90 \\
\hline High & 23 & 7 & 7 & $\begin{array}{l}\text { a vs c; } \\
\text { b vs c; }\end{array}$ & $\begin{array}{l}0.57 \\
0.50\end{array}$ \\
\hline \multicolumn{6}{|l|}{$V D$} \\
\hline Low & 25 & 9 & 5 & a $v s \mathrm{~b}$ & 0.89 \\
\hline High & 27 & 9 & 7 & $\begin{array}{l}\text { a vs c; } \\
\text { b vs c; }\end{array}$ & $\begin{array}{l}0.93 \\
0.94\end{array}$ \\
\hline
\end{tabular}

${ }^{\mathrm{a}}$ Tumors with absence or low FOXP1 reactivity (cancer cells with less than $10 \%$ of positive nuclei or with less than $50 \%$ of positive cytoplasmic staining).

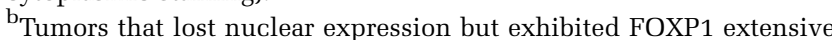
cytoplasmic reactivity in $>50 \%$ of cancer cells.

${ }^{\mathrm{C}}$ Tumors that exhibited nuclear FOXP1 localization in more than $10 \%$ of cancer cells.

Bold figures show statistically significant values.

with ER- $\alpha$ reactivity, while loss of ER- $\alpha$ expression was a frequent event in cases with FOXP1 expression in the cytoplasm or loss of FOXP1 expression.

\section{Survival Analysis}

Kaplan-Meier survival curves stratified for FOXP1 nuclear expression, FOXP1 cytoplasmic expression and combined nuclear/cytoplasmic patterns of expression are shown in Figure 2a-c, respectively. No significant association with survival was noted.

\section{Discussion}

In this study, we examined the expression of the FOXP1 transcription factor, a member of the 

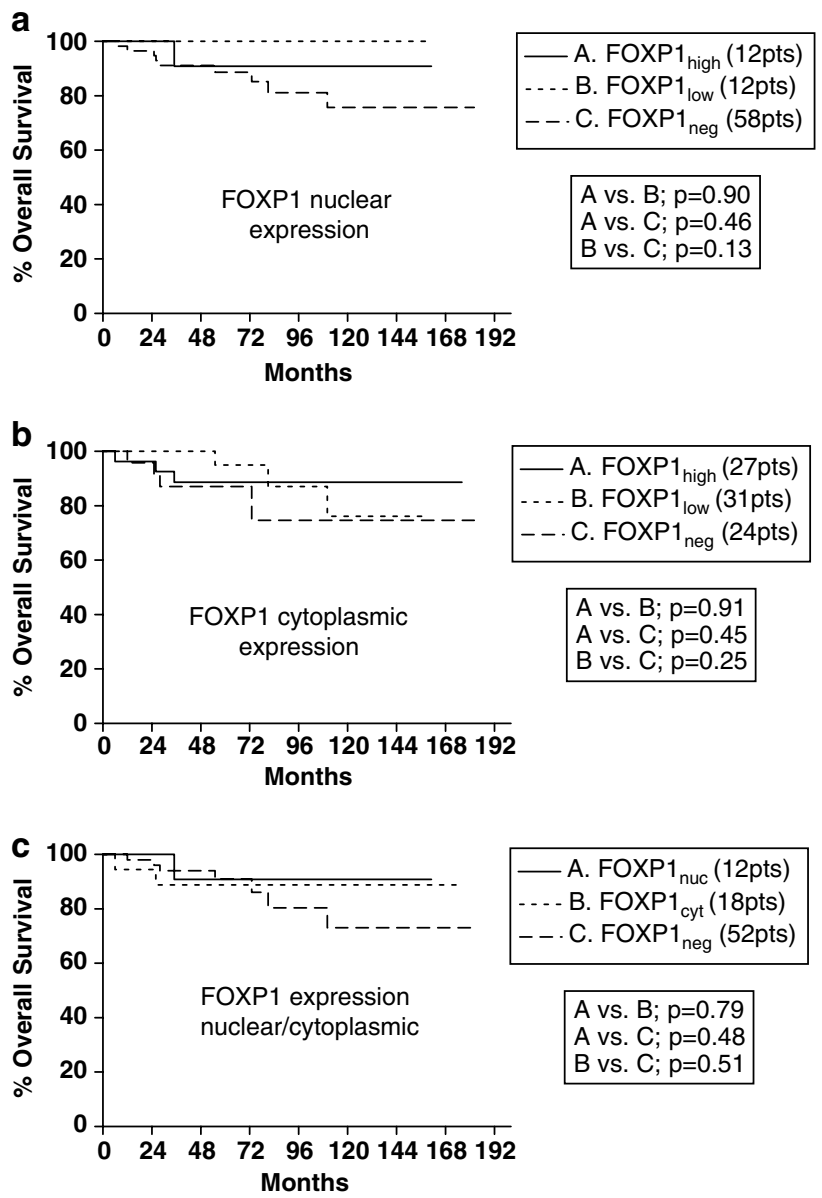

Figure 2 Kaplan-Meier survival curves in stage I endometrial cancer stratified for nuclear (a), cytoplasmic (b) and nuclear/ cytoplasmic (c) patterns of FOXP1 expression.

forkhead/winged helix family of proteins, in normal and malignant endometrium. The JC12 MoAb used was previously shown not to recognize the closely related FOXP2, FOXP3 and FOXP4 proteins. ${ }^{9}$ As expected from previous immunohistochemical studies showing a wide expression of the protein in normal tissues, FOXP1 was expressed in the nuclei and cytoplasm of normal cycling endometrium. The nuclear staining prevailing in the proliferative, estrogen dependent, phase of the menstrual cycle was absent during the secretory phase.

A striking loss of FOXP1 expression in malignant endometrium was noted, with $40 \%$ of cases exhibiting total lack of reactivity with the JC12 MoAb. Extensive cytoplasmic FOXP1 expression was recorded in $33 \%$ of cases, but approximately half of them lacked nuclear FOXP1 expression. In the remaining cancer cases, only limited nuclear or cytoplasmic expression was observed. This is particularly significant because malignant tissue is not typically characterized as hormonally regulated in a cyclic manner and endometrial adenocarcinoma displays an expression profile closer to normal proliferative than that of normal secretory endo- metrium. ${ }^{24}$ The mechanism of this loss of FOXP1 expression is unknown. Several studies have reported allelic deletions of the $3 p$ chromosome arm in endometrial cancer. ${ }^{1-3}$ As the FOXP1 gene resides in the 3p14.1 position, deletion or chromosomic imbalance of this region may contribute to the loss of FOXP1 expression in endometrial cancer. However, a preliminary study of a small number of cases by fluorescent in situ hybridization (FISH), using FOXP1 gene probes, found that two cases which were negative for FOXP1 protein expression both gave dual FOXP1 FISH signals (AHB and Roland Ventura, unpublished data). Thus, in these cases, copy number changes did not appear to reflect the loss of FOXP1 expression.

Nuclear FOXP1 expression was associated significantly with the expression of ER- $\alpha$ and marginally with PgR expression as previously reported in breast cancer by Fox et al. ${ }^{8}$ However, this group observed no direct regulation of FOXP1 expression levels by estrogen in experiments with the ERpositive MCF-7 cell line. This is interesting in the context of the fluctuations of FOXP1 expression in the normal endometrium, as these would normally indicate that its expression was hormonally regulated. Nevertheless, other members of the FOX family, such as FOXO3a/FKHRL-1, do regulate ER- $\alpha$ gene transcription and interact with ER- $\alpha$ in the presence of beta estradiol. ${ }^{25-27}$ The biological importance of an association with nuclear FOXP1 expression and ER- $\alpha$ positivity is that the nuclear receptor box in the FOXP1 protein may also enable it to act as a coregulator of ER- $\alpha$.

An interesting finding in the current work is the direct association of exclusively cytoplasmic expression of FOXP1 with HIF- $1 \alpha$ overexpression. Nuclear/cytoplasmic shuttling of members of the forkhead protein family (ie FOXO1) has been reported to occur as a result of protein phosphorylation. ${ }^{28}$ Phosphorylation of FKHRL1 via a phosphatidylinositol 3-kinase/Akt kinase results in cytoplasmic shuttling of the protein, ${ }^{29}$ which suggests that similar mechanisms may be also involved in FOXP1 cytoplasmic localization. Given that hypoxia both enhances Act activity ${ }^{30}$ and induces HIF- $1 \alpha$ and $-2 \alpha$ overexpression, the significant association between the cytoplasmic localization of FOXP1 and HIF- $1 \alpha$ overexpression may be the result of a single cause, namely hypoxia. Several studies also suggested that Act significantly contributes to HIF-1 $\alpha$ stabilization. ${ }^{31,32}$ A direct role of FOXP1 in HIF regulation cannot however, be excluded as a recent study indicated that the nuclear FOXO4 protein downregulates HIF-1 $\alpha$ through prolyl hydroxylase/pVHL-independent transcriptional pathway. ${ }^{33}$

The biological consequences of the cytoplasmic localization of FOXP1 or its overall loss of expression are obscure. The ability of FOXP1 to interact with other proteins, which may then be functionally removed from the nucleus through interaction with 
cytoplasmic FOXP1, provides one possible explanation as to why tumors with cytoplasmic expression might differ biologically from those that are FOXP1 negative. Apart from HIF-1 $\alpha$ overexpression, the cytoplasmic FOXP1 expression pattern was linked with deep myometrial invasion and with poor differentiation, although this latter finding did not reach a level of statistical significance, probably because of the low number of cases analyzed. Despite the lack of any important prognostic association, survival curves revealed that loss of the FOXP1 protein confers a slightly worse outcome even in this highly curable stage of the disease. The associations with ER and prognosis are similar to those found in the study of Fox et $a l^{9}$ in breast cancer. Abrogation of the FOXP1 suppressor activity may release a molecular cascade important for transformation and tumor progression. Although genes transcriptionally regulated by FOXP1 are unknown as yet, the herein reported association with HIF-1 $\alpha$ overexpression and nuclear expression in proliferative endometrium certainly points towards a pathway related to tumor aggressiveness. The prognostic importance of FOXP1 loss of expression may have been revealed more effectively in advanced stages of the disease, where mortality is higher, but such cases were not included in our series. This study provides evidence on pathways to be investigated to elucidate the interplay between FOXP1, ER and HIF-1 $\alpha$ in hormone-dependent cancers.

\section{Acknowledgements}

AHB is supported by the Leukaemia Research Fund. The study was financially supported by the Tumour and Angiogenesis Research group.

\section{References}

1 Fujino T, Risinger JI, Collins NK, et al. Allelotype of endometrial carcinoma. Cancer Res 1994;54:42944298.

2 Arlt MF, Herzog TJ, Mutch DG, et al. Loss of heterozygosity of chromosome $3 p$ sequences is an infrequent event in endometrial cancer. Gynecol Oncol 1996;60:308-312.

3 Jones MH, Nakamura Y. Deletion mapping of chromosome $3 p$ in female genital tract malignancies using microsatellite polymorphisms. Oncogene 1992;7:16311634.

4 Banham A, Beasley N, Campo E, et al. The FOXP1 winged helix transcription factor is a novel candidate tumor suppressor gene on chromosome $3 \mathrm{p} 1$. Cancer Res 2001;61:8820-8829.

5 Carlson P, Mahlapuu M. Forkhead transcription factors: key players in development and metabolism. Dev Biol 2002;250:1-23.

6 Banham AH, Connors JM, Brown PJ, et al. Expression of the FOXP1 transcription factor is strongly associated with inferior survival in patients with diffuse large B-cell lymphoma. Clin Cancer Res 2005;11:1065-1072.

7 Barrans SL, Fenton JA, Banham A, et al. Strong expression of FOXP1 identifies a distinct subset of diffuse large B-cell lymphoma (DLBCL) patients with poor outcome. Blood 2004;104:2933-2935.

8 Streubel B, Vinatzer U, Lamprecht A, et al. $\mathrm{T}(3 ; 14)(\mathrm{p} 14.1 ; \mathrm{q} 32)$ involving IGH and FOXP1 is a novel recurrent chromosomal aberration in MALT lymphoma. Leukaemia 2005;19:652-658.

9 Fox SB, Brown P, Han C, et al. Expression of the forkhead transcription factor FOXP1 is associated with estrogen receptor alpha and improved survival in primary human breast carcinomas. Clin Cancer Res 2004;10:3521-3527.

10 Wang B, Weidenfeld J, Lu MM, et al. Foxp1 regulates cardiac outflow tract, endocardial cushion morphogenesis and myocyte proliferation and maturation. Development 2004;131:4477-4487.

11 Wang B, Weidenfeld J, Lu MM, et al. Foxp1 regulates cardiac outflow tract, endocardial cushion morphogenesis and myocyte proliferation and maturation. Development 2004;131:4477-4487.

12 Noyes RW, Hertig AT, Rock J, et al. Dating the endometrial biopsy. Fertil Steril 1950;1:3-25.

13 Longacre TA, Kempson RL, Hendrickson MR. Endometrial hyperplasia, metaplasia and carcinoma. In: Fox H, Wells M (eds). Haines and Taylor Obstetrical and Gynaecological Pathology, 4th edn. Churchill Livingstone: New York, 1995, pp 421-510.

14 Silverberg SG, Kurman RJ. Endometrial carcinoma. In: Silverberg SG, Kurman RJ (eds). Tumours of the Uterine Corpus and Gestational Trophoblastic Disease. Atlas of Tumor Pathology. Third Series. Fasicle 3. Armed Forces Institute of Pathology: Washington, DC, 1992, pp 47-89.

15 Sivridis E, Giatromanolaki A, Gatter KC, et al. Tumor and Angiogenesis Research Group. Association of hypoxia-inducible factors 1alpha and 2alpha with activated angiogenic pathways and prognosis in patients with endometrial carcinoma. Cancer 2002;95: 1055-1063.

16 Giatromanolaki A, Sivridis E, Koukourakis MI, et al. Intratumoral angiogenesis: a new prognostic indicator for stage I endometrial adenocarcinomas? Oncol Res 1999;11:205-212.

17 Giatromanolaki A, Sivridis E, Brekken R, et al. Tumour and Angiogenesis Research Group. The angiogenic 'vascular endothelial growth factor/flk-1(KDR) receptor' pathway in patients with endometrial carcinoma: prognostic and therapeutic implications. Cancer 2001; 92:2569-2577.

18 Sivridis E, Giatromanolaki A, Koukourakis M, et al. Endometrial carcinoma: association of steroid hormone receptor expression with low angiogenesis and bcl-2 expression. Virchows Arch 2001;438:470-477.

19 Talks KL, Turley H, Gatter KC, et al. The expression and distribution of the hypoxia-inducible factors HIF1alpha and HIF-2alpha in normal human tissues, cancers, and tumor-associated macrophages. Am J Pathol 2000;157:411-421.

20 Zhong H, De Marzo AM, Laughner E, et al. Overexpression of hypoxia-inducible factor 1alpha in common human cancers and their metastases. Cancer Res 1999;59:5830-5835.

21 Giatromanolaki A, Koukourakis MI, Sivridis E, et al. Relation of hypoxia inducible factor 1 alpha and 
2 alpha in operable non-small cell lung cancer to angiogenic/molecular profile of tumours and survival. Br J Cancer 2001;85:881-890.

22 Koukourakis MI, Giatromanolaki A, Sivridis E, et al. Hypoxia-inducible factor (HIF1A and HIF2A), angiogenesis, and chemoradiotherapy outcome of squamous cell head-and-neck cancer. Int J Radiat Oncol Biol Phys 2002;53:1192-1202.

23 Giatromanolaki A, Sivridis E, Kouskoukis C, et al. Hypoxia-inducible factors 1alpha and 2alpha are related to vascular endothelial growth factor expression and a poorer prognosis in nodular malignant melanomas of the skin. Melanoma Res 2003;13: 493-501.

24 Mutter GL, Baak JP, Fitzgerald JT, et al. Global expression changes of constitutive and hormonally regulated genes during endometrial neoplastic transformation. Gynecol Oncol 2001;83:177-185.

25 Guo S, Sonenshein GE. Forkhead box transcription factor FOXO3a regulates estrogen receptor alpha expression and is repressed by the Her-2/neu/phosphatidylinositol 3-kinase/Akt signaling pathway. Mol Cell Biol 2004;24:8681-8690.

26 Schuur ER, Loktev AV, Sharma M, et al. Liganddependent interaction of estrogen receptor-alpha with members of the forkhead transcription factor family. J Biol Chem 2001;276:33554-33560.

27 Zhao HH, Herrera RE, Coronado-Heinsohn E, et al. Forkhead homologue in rhabdomyosarcoma functions as a bifunctional nuclear receptor-interacting protein with both coactivator and corepressor functions. J Biol Chem 2001;276:27907-27912.

28 Zhao X, Gan L, Pan H, et al. Multiple elements regulate nuclear/cytoplasmic shuttling of FOXO1: characterization of phosphorylation-and 14-3-3-dependent and-independent mechanisms. Biochem J 2004;378: 839-849.

29 Arimoto-Ishida E, Ohmichi M, Mabuchi S, et al. Inhibition of phosphorylation of a forkhead transcription factor sensitizes human ovarian cancer cells to cisplatin. Endocrinology 2004;145:2014-2022.

30 Andreucci M, Michael A, Kramers C, et al. Renal ischemia/reperfusion and ATP depletion/repletion in LLC-PK(1) cells result in phosphorylation of FKHR and FKHRL1. Kidney Int 2003;64:1189-1198.

31 Mottet D, Dumont V, Deccache Y, et al. Regulation of hypoxia-inducible factor-1alpha protein level during hypoxic conditions by the phosphatidylinositol 3-kinase/Akt/glycogen synthase kinase 3beta pathway in HepG2 cells. J Biol Chem 2003;278: 31277-31285.

32 Zhou J, Schmid T, Frank R, et al. PI3K/Akt is required for heat shock proteins to protect hypoxia-inducible factor 1alpha from pVHL-independent degradation. J Biol Chem 2004;279:13506-13513.

33 Tang TT, Lasky LA. The forkhead transcription factor FOXO4 induces the down-regulation of hypoxiainducible factor 1 alpha by a von Hippel-Lindau protein-independent mechanism. J Biol Chem 2003; 278:30125-30135. 